\title{
Short versus standard esophageal myotomy in achalasia patients: a systematic review and meta-analysis of comparative studies
}

\section{(ㄷ)(우우}

\section{Authors}

Saurabh Chandan', Antonio Facciorusso², Shahab R. Khan ${ }^{3}$, Daryl Ramai ${ }^{4}$, Babu P. Mohan ${ }^{5}$, Mohammad Bilal ${ }^{6}$, Banreet Dhindsa $^{7}$, Lena L. Kassab ${ }^{8}$, Hemant Goyal ${ }^{9}$, Abhilash Perisetti ${ }^{10}$, Ishfaq Bhat ${ }^{7}$, Shailender Singh ${ }^{7}$, Stephanie McDonough $^{5}$, Douglas G. Adler ${ }^{5}$

Institutions

1 Division of Gastroenterology and Hepatology, $\mathrm{CHI}$ Creighton University Medical Center, Omaha, Nebraska, United States

2 Gastroenterology Unit, Department of Surgical and Medical Sciences, University of Foggia, Foggia, Italy

3 Section of Gastroenterology, Rush University Medical Center, Chicago, Illinois, United States

4 Internal Medicine, Brooklyn Hospital Center, Brooklyn, New York, United States

5 Division of Gastroenterology and Hepatology, University of Utah School of Medicine, Salt Lake City, Utah, United States

6 Division of Gastroenterology, University of Minnesota and Minneapolis VA Health Care System, Minneapolis, Minnesota, United States

7 Gastroenterology and Hepatology, University of Nebraska Medical Center, Omaha, Nebraska, United States

8 Internal Medicine, Mayo Clinic, Rochester, Minnesota, United States

9 Gastroenterology, Wright Center for Graduate Medical Education, Scranton, Philadelphia, United States

10 Gastroenterology and Hepatology, University of Arkansas for Medical Sciences, Little Rock, Arkansas, United States

submitted 14.12 .2020

accepted after revision 17.3.2021

\section{Bibliography}

Endosc Int Open 2021; 09: E1246-E1254

DOI 10.1055/a-1490-8493

ISSN 2364-3722

(c) 2021. The Author(s).

This is an open access article published by Thieme under the terms of the Creative Commons Attribution-NonDerivative-NonCommercial License, permitting copying and reproduction so long as the original work is given appropriate credit. Contents may not be used for commercial purposes, or adapted, remixed, transformed or built upon. (https://creativecommons.org/licenses/by-nc-nd/4.0/)
Georg Thieme Verlag KG, Rüdigerstraße 14,

70469 Stuttgart, Germany

Corresponding author

Douglas G. Adler, MD, Gastroenterology and Hepatology, University of Utah School of Medicine, Huntsman Cancer Center, 30N 1900E 4R118, Salt Lake City, Utah 84132, United States

Fax: +1-801-581-8007

Douglas.adler@hsc.utah.edu

Supplementary material is available under https://doi.org/10.1055/a-1490-8493

\section{ABSTRACT}

Background and study aims Despite the clinical efficacy of peroral endoscopic myotomy (POEM), postoperative symptomatic gastroesophageal reflux disease (GERD) remains a major concern. While it is known that length of the gastric myotomy affects postoperative GERD, the clinical relevance of variation in esophageal myotomy length is not well known. We performed a systematic review and meta-analysis of studies comparing outcomes of short versus standard myotomy length in patients with achalasia.

Patients and methods We searched multiple databases from inception through November 2020 to identify studies that reported on outcomes of achalasia patients who underwent short compared with standard esophageal myotomy. Meta-analysis was performed to determine pooled odds ratio (OR) of clinical success, GERD outcomes, and adverse events with the two techniques.

Results 5 studies with 474 patients were included in the final analysis (short myotomy group 214, standard myotomy group 260). There was no difference in clinical success (OR $1.17,95 \%$ confidence interval $[\mathrm{CI}] 0.54-2.52 ; 120 \% ; P=$ 0.69 ), postoperative symptomatic GERD (OR $0.87,95 \% \mathrm{Cl}$ $0.44-1.74 ; 1229 \% ; P=0.70)$, and overall adverse events (OR 0.52, 95\%Cl 0.19-1.38; I2 40\%; $P=0.19$ ), between the 
two groups. Incidence of postoperative erosive esophagitis as determined by endoscopy was lower in the short myotomy group (OR 0.50, 95\%Cl 0.24-1.03; I2 0\%; $P=0.06$ ).
Conclusion Our analysis showed that performing POEM with short esophageal myotomy in achalasia was as safe and effective as standard myotomy, with lower incidence of postoperative erosive esophagitis.

\section{Introduction}

Achalasia is a primary esophageal motor disorder, typically of unclear etiology. The disorder is characterized by degeneration of the myenteric plexus resulting in impaired relaxation of the esophagogastric junction and loss of organized peristalsis in the esophageal body causing patients to experience dysphagia, esophageal dilation, food accumulation, and regurgitation [1]. Achalasia is a rare disease with a globally reported incidence varying from 0.03 to 1.63 per 100000 persons per year [2]. Treatment options include pharmacotherapy using muscle relaxants, endoscopic injection of botulinum toxin, pneumatic balloon dilation, and laparoscopic Heller myotomy (LHM) [3]. Peroral endoscopic myotomy (POEM) is a novel and minimally invasive therapeutic modality for achalasia and related disorders, which was first reported by Inoue et al. in 2010 [4]. While studies have shown POEM to be as safe and effective, with shorter recovery times and fewer serious complications compared with LHM $[5,6]$, guidelines suggest that both modalities are comparable treatment options for management of patients with achalasia types I and II [7].

Despite the clinical efficacy of POEM, postoperative symptomatic gastroesophageal reflux disease (GERD) remains a major concern $[8,9]$. A study comparing outcomes of LHM and POEM found that at 3 months, $57 \%$ of patients in the POEM group and $20 \%$ of patients in the LHM group had reflux esophagitis, as assessed by endoscopy. The incidence at 24 months was $44 \%$ and $29 \%$, respectively [10]. While several studies have identified risk factors for post-POEM reflux such as female sex, presence of preoperative esophagitis, as well as high preoperative Eckardt score, the effect of procedural factors such as overall length of myotomy on post-procedure reflux is debatable [11, 12]. Based on the available evidence and following the tenets of LHM, the actual myotomy length is recommended to be at least $6 \mathrm{~cm}(2 \mathrm{~cm}$ in the esophagus, $2-3 \mathrm{~cm}$ lower esophageal sphincter, $2 \mathrm{~cm}$ cardia) and on average between 8 and $10 \mathrm{~cm}$ [13]. The length of the gastric myotomy and its effect on reflux has been reported in the literature $[14,15]$. At present, the clinical relevance of esophageal myotomy length is not well known. We performed a systematic review and meta-analysis of studies comparing outcomes of short vs. standard myotomy length in patients with achalasia.

\section{Patients and methods}

\section{Search strategy}

The relevant medical literature was searched by a medical librarian for studies reporting outcomes of short vs. standard myotomy in patients with achalasia. The search strategy was created using a combination of keywords and standardized index terms. A systematic and detailed search was run in November 2020 in Ovid EBM Reviews, ClinicalTrials.gov, Ovid Embase (from 1974), Ovid Medline (from 1946 including epub ahead of print, in-process, and other non-indexed citations), Scopus (from 1970), and Web of Science (from 1975). Results were limited to English language only.

The full search strategy is available in Supplementary Appendix 1s. As the included studies were observational in design, the MOOSE (Meta-analyses Of Observational Studies in Epidemiology) Checklist was followed [16] and is provided as Supplementary Appendix 2s. The PRISMA checklist [17] and PRISMA flow chart for study selection [18] were followed and are provided as Supplementary Appendix 3s and Supplementary Fig.1s, respectively. Reference lists of evaluated studies were examined to identify other studies of interest.

\section{Study selection}

In this meta-analysis, we only included studies that compared the clinical outcomes of short vs. standard esophageal myotomy in patients with achalasia. Studies included were randomized controlled trials (RCTs), cohort, and case-control studies that reported outcomes of both treatment approaches. Studies were included irrespective of whether they were published as full manuscripts or conference abstracts, performed in inpatient or outpatient setting, follow-up time, and country of origin, provided they included the appropriate data needed for the analysis.

Our exclusion criteria were as follows: 1) studies reporting outcomes of POEM in non-achalasia disorders; 2) case reports and case series studies; 2) studies with sample size $<10$ patients; 3) studies performed in the pediatric population (age $<18$ years); and 4) studies not published in the English language. In cases of multiple publications from a single research group reporting on the same patient cohort and/or overlapping cohorts, data from the most recent and/or most appropriate comprehensive report were retained. The remaining studies were evaluated by two authors (S.C., D.R.) based on the publication timing (most recent) and/or the sample size of the study (largest). In situations where a consensus could not be reached, overlapping studies were included in the final analysis and any potential effects were assessed by sensitivity analysis of the pooled outcomes by leaving out one study at a time.

\section{Data abstraction and quality assessment}

Data on study-related outcomes from the individual studies were abstracted independently onto a standardized form by at least two authors (S.C., S.R.K.). Authors (A.P., B.D., D.R.) crossverified the collected data for possible errors, and two authors 
(S.C., S.R.K.) performed the quality scoring independently. We used the Newcastle-Ottawa scale to assess the quality of cohort studies [19]. This quality score consisted of eight questions, the details of which are provided in Supplementary Table 1s. For RCTs, we used the Cochrane Collaboration tool to assess risk of bias (Supplementary Appendix 4s) [20]. The quality of evidence was assessed using the Grading of Recommendations Assessment, Development and Evaluation (GRADE) methodology and is depicted as per Supplementary Fig. 2s [21].

\section{Outcomes assessed}

Patients were grouped based on the intervention they received: short esophageal myotomy or standard esophageal myotomy. The following outcomes were assessed:

1. pooled odds ratio $[O R]$ and proportion of clinical success (defined as postoperative Eckardt score <3 [22-25] or $<4$ [26])

2. pooled OR and proportion of symptomatic postoperative GERD

3. pooled OR and proportion of postoperative erosive esophagitis as determined by endoscopic evaluation

4. pooled OR and proportion of overall adverse events

5. pooled OR and proportion of mucosal injury in both groups

6. pooled means of length of hospital stay (LOS) in both groups.

\section{Statistical analysis}

We used meta-analysis techniques to calculate the pooled estimates in each case following the methods suggested by DerSimonian and Laird using the random-effects model and results were expressed in terms of odds ratio (OR) or mean difference along with relevant $95 \%$ confidence intervals $(\mathrm{Cls})$, when appropriate [27]. When the incidence of an outcome was zero in a study, a continuity correction of 0.5 was added to the number of incident cases before statistical analysis.

We assessed heterogeneity between study-specific estimates by using Cochran Q statistical test for heterogeneity, 95 $\% \mathrm{Cls}$, and the 12 statistics [28-30]. Values of $<30 \%, 30 \%-60 \%$, $61 \%-75 \%$, and $>75 \%$ were suggestive of low, moderate, substantial, and considerable heterogeneity, respectively. We assessed publication bias qualitatively, by visual inspection of funnel plot, and quantitatively, by the Egger test [31]. When publication bias was present, further statistics using the fail-Safe $\mathrm{N}$ test and Duval and Tweedie's "Trim and Fill” test was used to ascertain the impact of the bias [32].

Given the low number of included studies, a Knapp-Hartung two-tailed $P$ value of $<0.10$ was considered statistically significant and $R^{2}$ value was calculated to study the goodness-of-fit [33]. All analyses were performed using RevMan version 5 from the Cochrane collaboration (Cochrane Collaboration, Copenhagen, Denmark) and OpenMeta [Analyst] software.

\section{Results}

\section{Characteristics and quality of included studies}

Five studies were included in the final analysis [22-26]. Two of the included studies were retrospective in design [24,25] and two were prospective RCTs [22, 23]. One of the studies was published in abstract form, presenting interim analyses [26]. Three studies were performed in China, one in Europe, and one in India. Based on the Newcastle-Ottawa scoring system, both observational cohort studies were considered to be of high quality (Supplementary Table 1s).

\section{Search results and population characteristics}

All search results were exported to Endnote where 5536 obvious duplicates were removed leaving 4666 citations. Five studies with a total of 474 patients were included in the final analysis. A schematic diagram demonstrating our study selection is illustrated in Supplementary Fig. 1s.

A total of 214 patients underwent POEM with a short esophageal myotomy, ranging from $2.76 \mathrm{~cm}$ to $5 \mathrm{~cm}$, and $260 \mathrm{pa}-$ tients underwent a standard esophageal myotomy, ranging from $6.9 \mathrm{~cm}$ to $10 \mathrm{~cm}$. Across all studies, the mean gastric myotomy length was kept the same in both the short and standard groups, ranging from $2 \mathrm{~cm}$ to $3.2 \mathrm{~cm}$ [22-26]. Details of patient characteristics and demographics were available in all five studies. A total of 238 males and 236 females were included in our analysis. The etiology was Type I achalasia in 106 patients, Type II in 364 patients, and Type III in 4 patients. Mean age ranged from 37.7 years to 49.3 years. LOS ranged from 2.81 to 9.9 days. Mean follow-up time ranged from 8.09 to 26.8 months in the short myotomy group and from 8.3 to 29.5 months in the standard myotomy group.

Further details of patient characteristics, prior therapeutic interventions (botulinum toxin, pneumatic dilation, and/or LHM) are described in > Table 1 and $>$ Table 2.

\section{Meta-analysis outcomes}

1. The pooled rate of clinical success was $95.1 \%$ (95\% Cl $91.4-$ $98.7)$ in the short myotomy group and $93.3 \%$ (95\% Cl 89.197.5 ) in the standard myotomy group. There was no statistically significant difference between the two groups (OR 1.17, $95 \% \mathrm{Cl} 0.54-2.52 ; I^{2} 0 \% ; P=0.69$ ) (> Fig. 1).

2. The pooled rate of symptomatic postoperative GERD was $22.6 \%(95 \% \mathrm{Cl} 5.6-39.6)$ in the short myotomy group and $20.2 \%$ (95\% Cl 10.8-29.5) in the standard myotomy group. There was no statistically significant difference between the two groups (OR 0.87, $95 \% \mathrm{Cl} 0.44-1.74 ; P^{2} 29 \% ; P=0.70$ ) ( Fig. 2).

3. The pooled rate of postoperative erosive esophagitis as determined by endoscopy was $12.4 \%(95 \% \mathrm{Cl} 0-25.2)$ in the short myotomy group and $22.3 \%(95 \% \mathrm{Cl} 3.3-41.4)$ in the standard myotomy group. The difference between the two groups was statistically significant (OR $0.50,95 \% \mathrm{Cl} 0.24-$ $1.03 ; I^{2} 0 \% ; P=0.06$ ) ( Fig. 3 ).

4. The pooled rate of overall adverse events was $6.5 \%(95 \% \mathrm{Cl}$ $0.6-12.4)$ in the short myotomy group and $12.5 \%(95 \% \mathrm{Cl}$ 1.9-23.1) in the standard myotomy group. There was no 


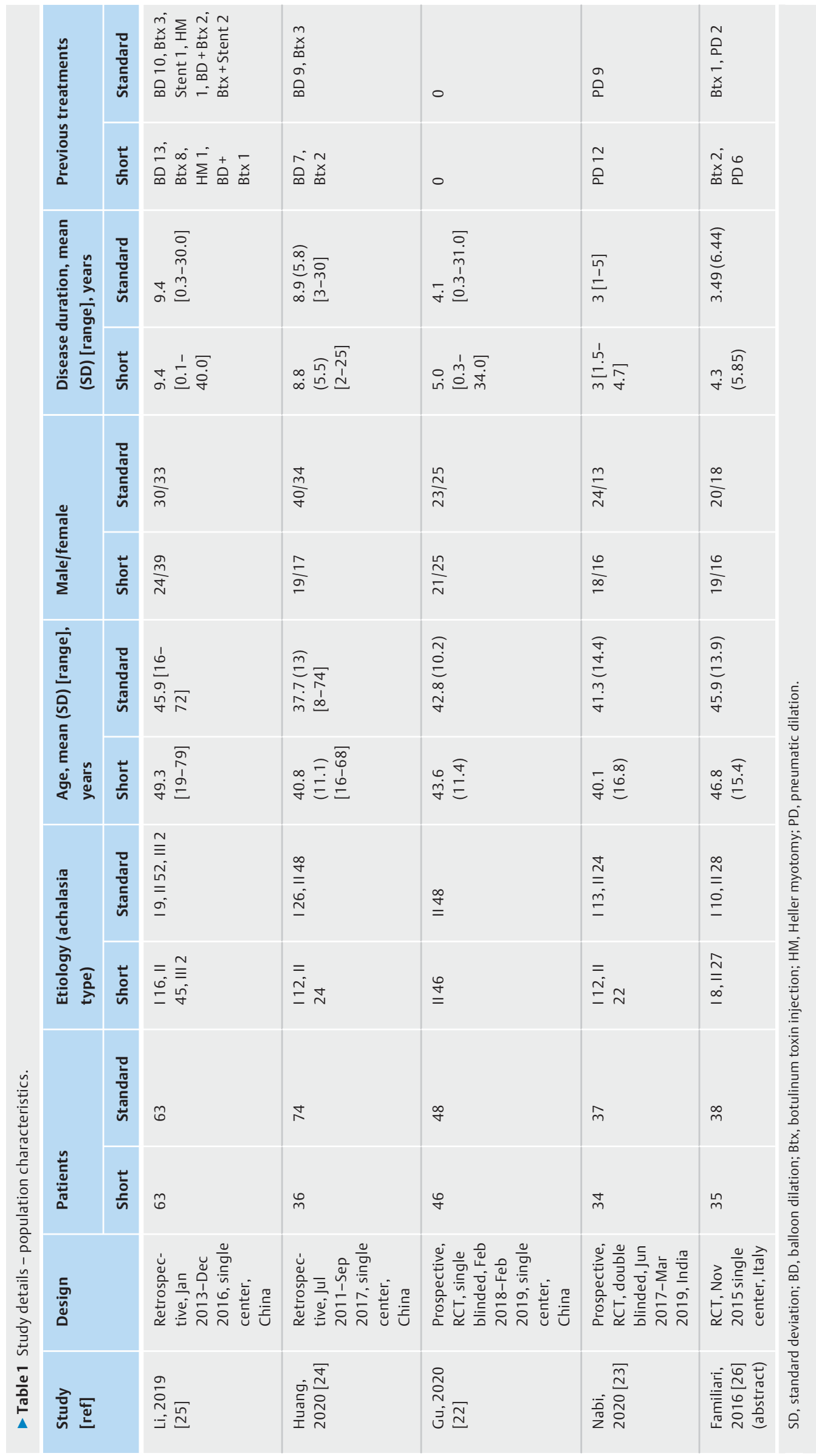




\begin{tabular}{|c|c|c|c|c|c|c|c|}
\hline \multirow{2}{*}{ 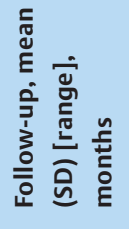 } & 咅 & 它 & 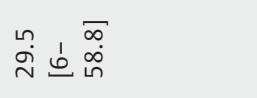 & $\simeq$ & $\simeq$ & 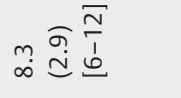 & 竞 \\
\hline & $\begin{array}{l}\frac{\hbar}{0} \\
\frac{1}{n}\end{array}$ & 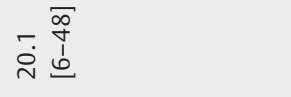 & 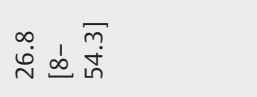 & $\simeq$ & $\simeq$ & 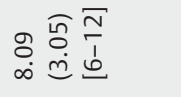 & 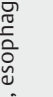 \\
\hline \multirow{2}{*}{ 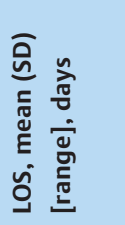 } & 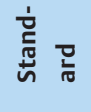 & $\stackrel{\underline{n}}{z}$ & 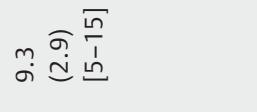 & 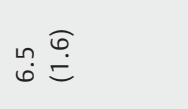 & $\begin{array}{l}\bar{\infty} \\
\stackrel{\widehat{N}}{\hat{i}}\end{array}$ & $\stackrel{m}{\stackrel{R}{i} \stackrel{F}{i}}$ & 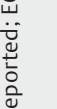 \\
\hline & $\begin{array}{l}\frac{\hbar}{0} \\
\frac{1}{n}\end{array}$ & $\frac{\alpha}{z}$ & 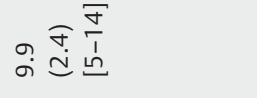 & $\stackrel{\widehat{\sigma}}{\stackrel{9}{\varrho}}$ & $\begin{array}{l}\sim \\
\infty \\
\sim \\
\sim\end{array}$ & 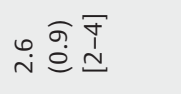 & 㐫 \\
\hline \multirow{2}{*}{ 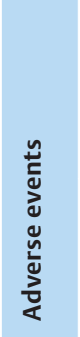 } & 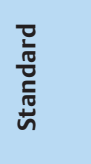 & 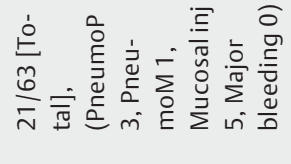 & 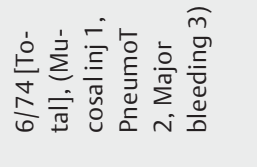 & 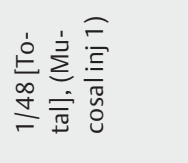 & 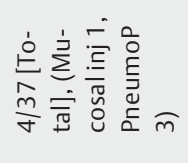 & 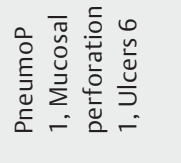 & 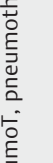 \\
\hline & 竞 & 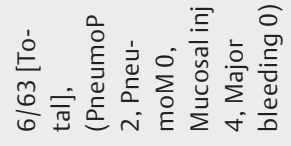 & 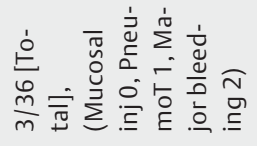 & 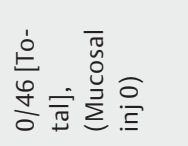 & 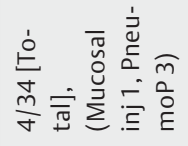 & 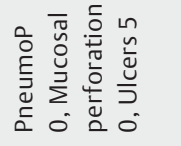 & 苾 \\
\hline \multirow{2}{*}{ 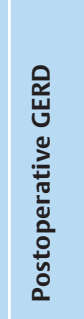 } & 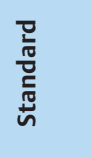 & 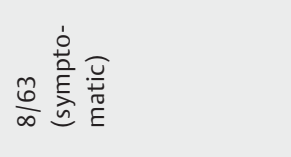 & 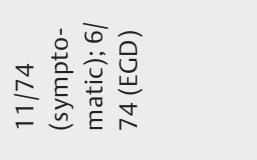 & 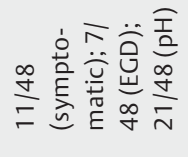 & 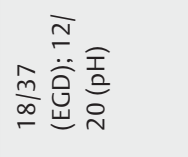 & 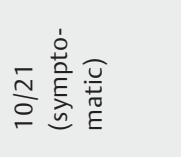 & 范 \\
\hline & 竞 & 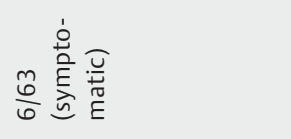 & 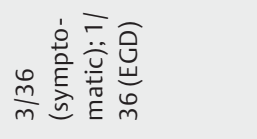 & 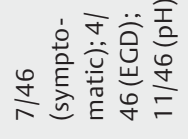 & 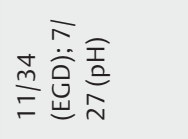 & 站 & 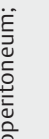 \\
\hline \multirow{2}{*}{ 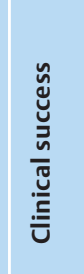 } & 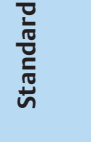 & 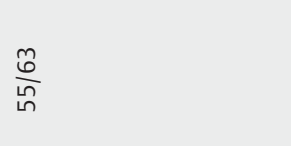 & $\frac{\hbar}{\infty}$ & $\frac{\infty}{\stackrel{\infty}{r}}$ & $\frac{m}{\stackrel{m}{N}}$ & 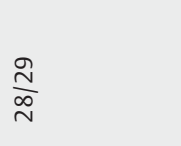 & 兽 \\
\hline & 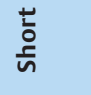 & $\frac{\hat{n}}{\stackrel{0}{0}}$ & $\underset{\substack{\infty \\
\frac{m}{m}}}{m}$ & $\frac{g}{\frac{f}{f}}$ & $\frac{\bar{m}}{\grave{N}}$ & 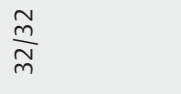 & 䒿 \\
\hline \multirow{2}{*}{ 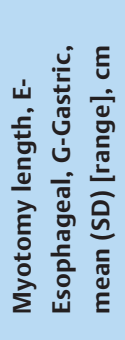 } & 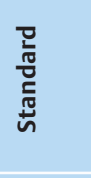 & 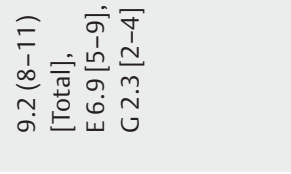 & 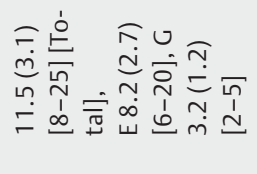 & 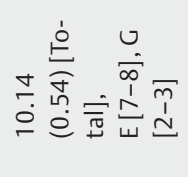 & 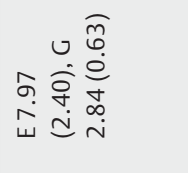 & 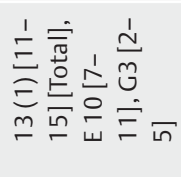 & 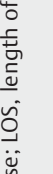 \\
\hline & 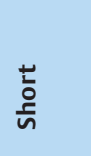 & 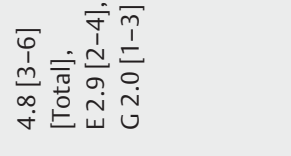 & 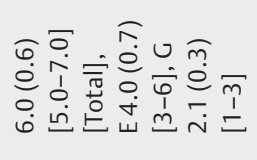 & 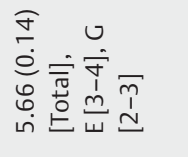 & 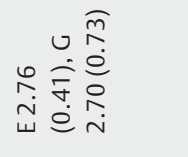 & 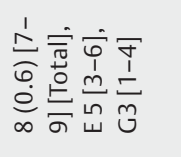 & 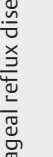 \\
\hline \multirow{2}{*}{ 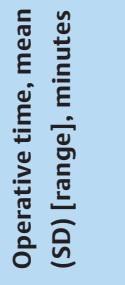 } & 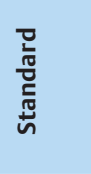 & 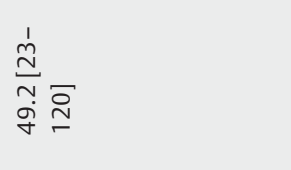 & 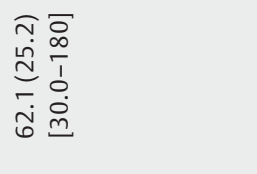 & $\begin{array}{l}\widehat{̃} \\
\stackrel{0}{0} \\
\underline{\sigma} \\
\dot{y}\end{array}$ & $\stackrel{m}{\stackrel{m}{i} \underset{\sim}{\stackrel{a}{d}}}$ & 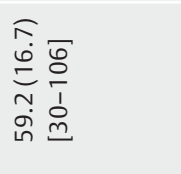 & 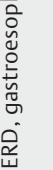 \\
\hline & 定 & $\stackrel{n}{\dot{m}} \stackrel{\frac{1}{\Sigma}}{\stackrel{\nabla}{\sim}}$ & 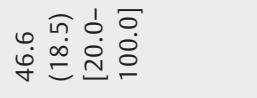 & $\stackrel{\sim}{\stackrel{\widehat{m}}{\stackrel{m}{m}}} \stackrel{0}{=}$ & 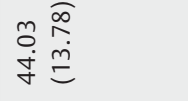 & 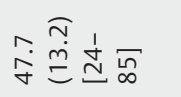 & \\
\hline \multicolumn{2}{|l|}{ 롤 } & $\begin{array}{l}\stackrel{\infty}{2} \\
\stackrel{i}{=}\end{array}$ & 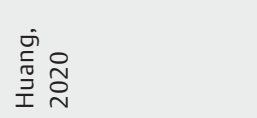 & 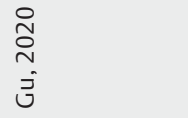 & 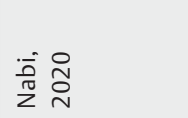 & 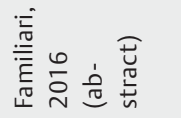 & 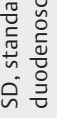 \\
\hline
\end{tabular}




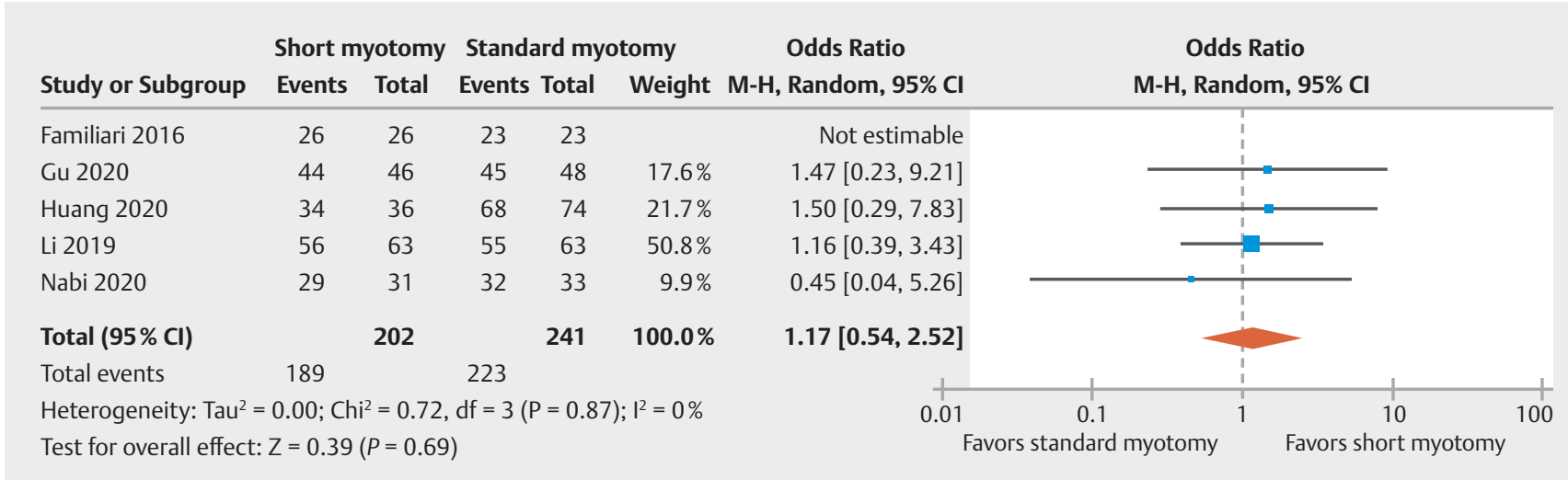

Fig. 1 Forest plot, clinical success. M-H, Mantel-Haenszel; Cl, confidence interval.

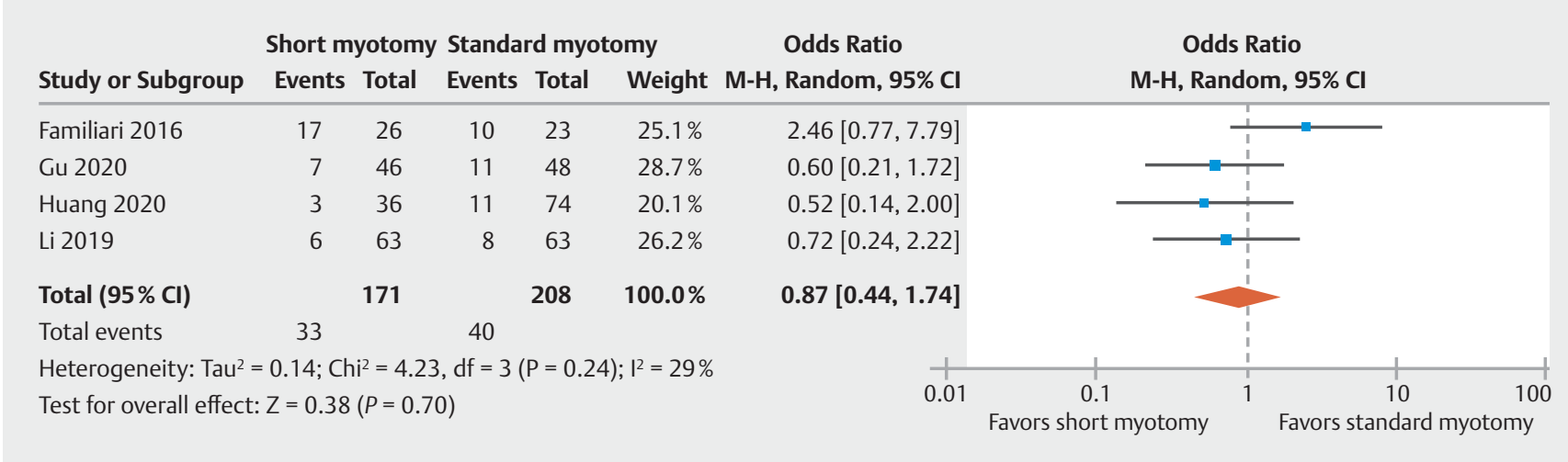

Fig. 2 Forest plot, postoperative symptomatic gastroesophageal reflux disease. M-H, Mantel-Haenszel; Cl, confidence interval.

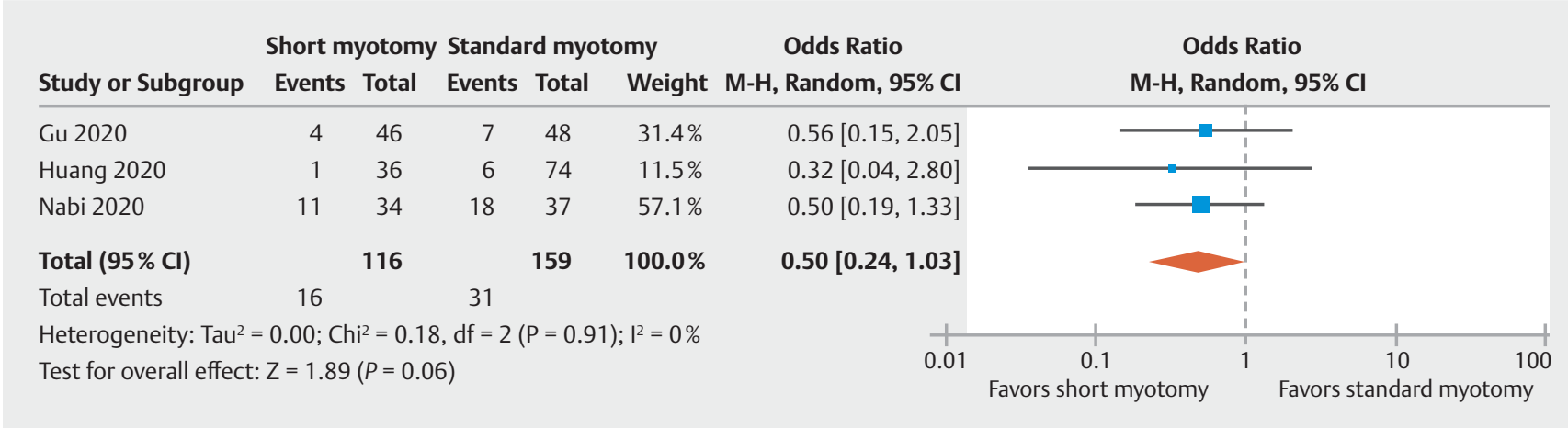

Fig. 3 Forest plot, postoperative erosive esophagitis. M-H, Mantel-Haenszel; $\mathrm{Cl}$, confidence interval.

statistically significant difference between the two groups (OR 0.52, $95 \% \mathrm{Cl} 0.19-1.38 ; I^{2} 40 \% ; P=0.19$ ) (Supplementary Fig. 3s).

5. The pooled rate of mucosal injury was $2 \%(95 \% \mathrm{Cl} 0-4)$ in the short myotomy group and $2.4 \%(95 \% \mathrm{Cl} 0.3-4.4)$ in the standard myotomy group. There was no statistically significant difference between the two groups (OR 0.74, 95\%Cl $\left.0.25-2.17 ; I^{2} 0 \% ; P=0.58\right)$ (Supplementary Fig. 4s).

6. The pooled mean LOS was 6.55 days $(95 \% \mathrm{Cl} 2.98-10.12)$ in the short myotomy group and 6.19 days ( $95 \% \mathrm{Cl} 2.47-9.91)$ in the standard myotomy group. There was no statistically significant difference between the two groups (OR 0.25 , $95 \% \mathrm{Cl}-0.14$ to $0.63 ; I^{2} 37 \% ; P=0.21$ ) (Supplementary Fig. 5s). All outcomes with $R^{2}$ values are summarized in - Table 3. 
- Table 3 Summary of pooled results.

\begin{tabular}{|l|c|c|c|}
\hline \multirow{2}{*}{ Outcome/group } & Pooled proportion, \% (95\%CI) & $\begin{array}{l}\text { OR (95\%CI), } \\
\text { P value, I2 }\end{array}$ \\
\hline & Short myotomy & Standard myotomy & $\begin{array}{l}1.17(0.54-2.52), \\
P=0.69,120 \%\end{array}$ \\
\hline Clinical success & $95.1(91.4-98.7)$ & $93.3(89.1-97.5)$ & $\begin{array}{l}0.87(0.44-1.74), \\
P=0.70,1229 \%\end{array}$ \\
\hline Postoperative GERD (symptomatic) & $22.6(5.6-39.6)$ & $20.2(10.8-29.5)$ & $\begin{array}{l}0.50(0.24-1.03), \\
P=0.06,120 \%\end{array}$ \\
\hline Postoperative GERD (EGD) & $12.4(0-25.2)$ & $22.3(3.3-41.4)$ & $\begin{array}{l}0.52(0.19-1.38), \\
P=0.19,1240 \%\end{array}$ \\
\hline Total adverse events & & $12.5(1.9-23.1)$ & $\begin{array}{l}0.74(0.25-2.17), \\
P=0.58,120 \%\end{array}$ \\
\hline Mucosal injury & $6.5(0.6-12.4)$ & $2.4(0.3-4.4)$ & $\begin{array}{l}0.25(-0.14-0.63), \\
P=0.21,1237 \%\end{array}$ \\
\hline Length of stay & $2(0-4)$ & $6.19(2.47-9.91)$ & \\
\hline CI, confidence interval; OR, odds ratio; GERD, gastroesophageal reflux disease; EGD, esophagogastroduodenoscopy.
\end{tabular}

\section{Validation of meta-analysis results}

Sensitivity analysis

To assess whether any one study had a dominant effect on the meta-analysis, we excluded one study at a time and analyzed its effect on the main summary estimate. We analyzed the effect of excluding the study by Familiari et al., published as an abstract, on clinical success. We found that exclusion of this study did not significantly affect the primary outcome or influence the heterogeneity.

\section{Heterogeneity}

We assessed dispersion of the calculated rates using the 12 percentage values as reported in the meta-analysis outcomes section. While the overall the heterogeneity was low, there was evidence of moderate heterogeneity in our secondary end points (i.e. overall adverse events and LOS).

\section{Publication bias}

Based on visual inspection of the funnel plot for clinical success and GERD outcomes, there was no evidence of publication bias (Supplementary Fig.6s).

\section{Discussion}

Our analysis shows that performing POEM with a shorter esophageal myotomy length in patients with achalasia is noninferior to standard length myotomy. While the incidence of postoperative symptomatic GERD was similar between the two groups, patients with shorter myotomies were statistically less likely to have endoscopic evidence of erosive esophagitis. The overall rates of adverse events, risk of mucosal injuries, and LOS were similar between the two groups of patients.

Since the first reports over a decade ago [4], POEM has become a standard treatment for achalasia and related disorders worldwide owing to its less invasive nature and higher curative effect than conventional therapeutic methods [34]. Despite the clinical efficacy of POEM, post-procedure GERD remains one of the most frequent complications encountered in clinical practice. Current evidence suggests that symptomatic GERD occurs in $8.5 \%-19 \%$ of patients, while endoscopic findings of erosive esophagitis are detected in $13 \%-29.4 \%$ of patients post-procedure [35-37]. Several procedural modifications have been made to POEM in an attempt to make the procedure safer, more effective, and the results more highly reproducible. Some of these modifications include a change in the myotomy approach (full thickness - when all muscle layers are cut; partial thickness - when only the circular layer is cut), location of the tunneling (anterior wall between 1 and 2 o'clock position; posterior wall between 5 and 6 o'clock position), and length of myotomy (long $\geq 7 \mathrm{~cm}$; or short $<7 \mathrm{~cm}$ ). While studies have shown that a gastric myotomy length of more than $2.5 \mathrm{~cm}$ results in increased rates of moderate esophagitis without improving overall clinical efficacy [15], the effect of altering esophageal myotomy length is not well established. Our study is the first in the literature to assess the effect of esophageal myotomy length on postoperative GERD and to analyze its effect on the clinical effectiveness of POEM.

Some of the commonly reported complications of POEM include mucosal perforations [38,39], pneumothorax [40], pneumoperitoneum [41,42], pneumomediastinum [43], and subcutaneous emphysema $[39,40,43]$. In our analysis, we found that while overall adverse events occurred in a greater proportion of patients undergoing standard length myotomy compared with those undergoing short myotomy, the difference between the two groups was not statistically significant. It is important to note that the operative time across studies was significantly longer when performing standard esophageal myotomy (45.6-72.43 vs. 31.2-47.7 minutes). We found no statistical difference in the pooled rates of mucosal injury between the two groups ( $2 \%$ vs. $2.4 \%$; $P=0.58$ ). Pneumoperitoneum was reported five patients, pneumothorax in one patient, and major 
bleeding in two patients in the short myotomy group. Finally, we found no difference in the overall LOS between the two groups.

There are several strengths to our review. First, we included only those studies where outcomes of short myotomy length were compared with those of the standard technique, including three RCTs $[22,23,26]$. This allowed us to perform a more robust meta-analysis of procedural outcomes. Second, given the significant differences in the incidence of GERD as assessed by symptomology, endoscopic evidence and $\mathrm{pH}$ monitoring [44], we calculated the pooled rates of symptomatic and erosive esophagitis separately. Third, we conducted a systematic literature search with well-defined inclusion criteria, careful exclusion of redundant studies, inclusion of good quality studies with detailed extraction of data and rigorous evaluation of study quality. Finally, we excluded all studies in which POEM was performed for non-achalasia indications such as jackhammer esophagus and diffuse esophageal spasm because of the variable lengths of myotomy in these conditions [45].

There are several limitations to this study, most of which are inherent to any meta-analysis. First, one of the included studies in our analysis only reported interim outcomes at 6 months [26], two studies reported outcomes at 12 months [22,23], and two studies reported outcomes beyond 20 months [24, 25]. The mean follow-up period varied across studies, ranging from 8.09 months to 29.5 months. While the overwhelming majority of patients $(n=364)$ included in our analysis had Type II achalasia, four patients had Type III achalasia. Although not standardized, a longer myotomy is thought to be more effective at controlling symptoms caused by the esophageal spasm of type III achalasia $[7,45,46]$. One of the included studies was published only in abstract format [26]. We contacted the authors via email to obtain details about patient characteristics and procedure outcomes, as reported in our study. However, we were informed that the trial is ongoing at this time. We were unable to compare short and long esophageal myotomy groups in terms of objective $\mathrm{pH}$-based outcomes of GERD (i.e. 24-hour $\mathrm{pH}$-impendence results), as this information was provided in only two trials $[22,23]$. Two of the studies included in our analysis were retrospective in design, and while they were both of high quality, their inclusion could have resulted in selection bias. The absence of blinding of outcome assessment by Gu et al. could have resulted in detection bias. Finally, we were unable to assess risk of bias in the study by Familiari et al., as it was only published as an abstract.

In conclusion, our study showed that performing POEM with short esophageal myotomy length appeared to be as clinically effective as standard myotomy. Both approaches had similar safety profiles. While incidence of symptomatic GERD was comparable between the two techniques, erosive esophagitis tended to occur less frequently with the short myotomy approach. It is important to note that statistical nonsignificance may not be an indication of equivalence but rather of uncertainty. Further RCTs with longer follow-up times are needed to validate our results.

\section{Competing interests}

The authors declare that they have no conflicts of interest.

\section{References}

[1] Vaezi MF, Pandolfino JE, Yadlapati RH et al. ACG Clinical Guidelines: Diagnosis and management of achalasia. Am J Gastroenterol 2020; 115: $1393-1411$

[2] Samo S, Carlson DA, Gregory DL et al. Incidence and prevalence of achalasia in central Chicago, 2004-2014, since the widespread use of high-resolution manometry. Clin Gastroenterol Hepatol 2017; 15: 366-373

[3] Boeckxstaens GE, Zaninotto G, Richter JE. Achalasia. Lancet 2014; 383: 83-93

[4] Inoue H, Minami H, Kobayashi Y et al. Peroral endoscopic myotomy (POEM) for esophageal achalasia. Endoscopy 2010; 42: 265-271

[5] Schneider AM, Louie BE, Warren HF et al. A matched comparison of per oral endoscopic myotomy to laparoscopic Heller myotomy in the treatment of achalasia. J Gastrointest Surg 2016; 20: 1789-1796

[6] Bhayani NH, Kurian AA, Dunst CM et al. A comparative study on comprehensive, objective outcomes of laparoscopic Heller myotomy with per-oral endoscopic myotomy (POEM) for achalasia. Ann Surg 2014; 259: 1098-1103

[7] Khashab MA, Vela MF, Thosani N et al. ASGE guideline on the management of achalasia. Gastrointest Endosc 2020; 91: 213-227

[8] Repici A, Fuccio L, Maselli R et al. GERD after per-oral endoscopic myotomy as compared with Heller's myotomy with fundoplication: a systematic review with meta-analysis. Gastrointest Endosc 2018; 87: 934-943

[9] Sanaka MR, Thota PN, Parikh MP et al. Peroral endoscopic myotomy leads to higher rates of abnormal esophageal acid exposure than laparoscopic Heller myotomy in achalasia. Surg Endosc 2019; 33: 2284-2292

[10] Werner YB, Hakanson B, Martinek J et al. Endoscopic or surgical myotomy in patients with idiopathic achalasia. N Engl J Med 2019; 381: $2219-2229$

[11] Kumbhari V, Familiari P, Bjerregaard NC et al. Gastroesophageal reflux after peroral endoscopic myotomy: a multicenter case-control study. Endoscopy 2017; 49: 634-642

[12] Arevalo G, Sippey M, Martin-Del-Campo LA et al. Post-POEM reflux: who's at risk? Surg Endosc 2020; 34: 3163-3168

[13] Stavropoulos SN, Desilets DJ, Fuchs KH et al. Per-oral endoscopic myotomy white paper summary. Surg Endosc 2014; 28: 2005-2019

[14] Oelschlager BK, Chang L, Pellegrini CA. Improved outcome after extended gastric myotomy for achalasia. Arch Surg 2003; 138: 490-497

[15] Grimes KL, Bechara R, Shimamura Y et al. Gastric myotomy length affects severity but not rate of post-procedure reflux: 3-year follow-up of a prospective randomized controlled trial of double-scope per-oral endoscopic myotomy (POEM) for esophageal achalasia. Surg Endosc 2020; 34: 2963-2968

[16] Stroup DF, Berlin JA, Morton SC et al. Meta-analysis of observational studies in epidemiology: a proposal for reporting. Meta-analysis Of Observational Studies in Epidemiology (MOOSE) group. JAMA 2000; 283: 2008-2012

[17] Liberati A, Altman DG, Tetzlaff J et al. The PRISMA statement for reporting systematic reviews and meta-analyses of studies that evaluate healthcare interventions: explanation and elaboration. BMJ 2009; 339: b2700 
[18] Moher D, Liberati A, Tetzlaff J et al. Preferred reporting items for systematic reviews and meta-analyses: the prisma statement. Ann Intern Med 2009; 151: 264-269

[19] Stang A. Critical evaluation of the Newcastle-Ottawa scale for the assessment of the quality of nonrandomized studies in meta-analyses. Eur J Epidemiol 2010; 25: 603-605

[20] Engels EA, Schmid CH, Terrin N et al. Heterogeneity and statistical significance in meta-analysis: an empirical study of 125 meta-analyses. Stat Med 2000; 19: 1707-1728

[21] Atkins D, Eccles M, Flottorp S et al. Systems for grading the quality of evidence and the strength of recommendations I: critical appraisal of existing approaches The GRADE Working Group. BMC Health Serv Res 2004; 4: 38

[22] Gu L, Ouyang Z, Lv L et al. Safety and efficacy of peroral endoscopic myotomy with standard myotomy versus short myotomy for treatment-naïve patients with type II achalasia: a prospective randomized trial. Gastrointest Endosc 2020: doi:10.1016/j.gie.2020.10.006

[23] Nabi Z, Ramchandani M, Sayyed M et al. Comparison of short versus long esophageal myotomy in cases with idiopathic achalasia: a randomized controlled trial. J Neurogastroenterol Motil 2020: doi:10.5056/jnm20022

[24] Huang S, Ren Y, Peng W et al. Peroral endoscopic shorter versus longer myotomy for the treatment of achalasia: a comparative retrospective study. Esophagus 2020; 17: 477-483

[25] Li L, Chai N, Linghu E et al. Safety and efficacy of using a short tunnel versus a standard tunnel for peroral endoscopic myotomy for Ling type IIc and III achalasia: a retrospective study. Surg Endosc 2019; 33 : 1394-1402

[26] Familiari P, Calì A, Landi R et al. Tu2041 Long vs short POEM for the treatment of achalasia. Interim analysis of a randomized controlled trial. Gastrointest Endosc 2016; 83: AB624

[27] DerSimonian R, Laird N. Meta-analysis in clinical trials. Control Clin Trials 1986; 7: 177-188

[28] Sutton A], Abrams KR, Jones DR et al. Methods for meta-analysis in medical research. New York: Wiley; 2000

[29] Mohan BP, Adler DG. Heterogeneity in systematic review and metaanalysis: how to read between the numbers. Gastrointest Endosc 2019; 89: 902-903

[30] Higgins ], Thompson SG, Spiegelhalter D]. A re-evaluation of randomeffects meta-analysis. J R Stat Soc Ser A Stat Soc 2009; 172: 137-159

[31] Higgins JP, Thompson SG, Deeks JJ et al. Measuring inconsistency in meta-analyses. BMJ 2003; 327: 557-560
[32] Duval S, Tweedie R. Trim and fill: a simple funnel-plot-based method of testing and adjusting for publication bias in meta-analysis. Biometrics 2000; 56: 455-463

[33] Greenland S, Senn SJ, Rothman KJ et al. Statistical tests, P values, confidence intervals, and power: a guide to misinterpretations. Eur J Epidemiol 2016; 31: 337-350

[34] Inoue H, Shiwaku H, Iwakiri K et al. Clinical practice guidelines for peroral endoscopic myotomy. Dig Endosc 2018; 30: 563-579

[35] Schlottmann F, Luckett DJ, Fine J et al. Laparoscopic Heller myotomy versus peroral endoscopic myotomy (POEM) for achalasia: a systematic review and meta-analysis. Ann Surg 2018; 267: 451-460

[36] Repici A, Fuccio L, Maselli R et al. GERD after per-oral endoscopic myotomy as compared with Heller's myotomy with fundoplication: a systematic review with meta-analysis. Gastrointest Endosc 2018; 87 : 934-943

[37] Akintoye E, Kumar N, Obaitan I et al. Peroral endoscopic myotomy: a meta-analysis. Endoscopy 2016; 48: 1059-1068

[38] Inoue $\mathrm{H}$, Sato $\mathrm{H}$, Ikeda $\mathrm{H}$ et al. Per-oral endoscopic myotomy: a series of 500 patients. J Am Coll Surg 2015; 221: 256-264

[39] Martinek J, Svecova H, Vackova Z et al. Per-oral endoscopic myotomy (POEM): mid-term efficacy and safety. Surg Endosc 2018; 32: 12931302

[40] Pannu D, Yang D, Abbitt PL et al. Prospective evaluation of CT esophagram findings after peroral endoscopic myotomy. Gastrointest Endosc 2016; 84: 408-415

[41] Yang S, Zeng MS, Zhang ZY et al. Pneumomediastinum and pneumoperitoneum on computed tomography after peroral endoscopic myotomy (POEM): postoperative changes or complications? Acta Radiol 2015; 56: 1216-1221

[42] Levy JL, Levine MS, Rubesin SE et al. Findings of esophagography for 25 patients after peroral endoscopic myotomy for achalasia. AJR Am J Roentgenol 2016; 207: 1185-1193

[43] Jayan N, Jacob JS, Mathew M et al. Anesthesia for peroral endoscopic myotomy: a retrospective case series. J Anaesthesiol Clin Pharmacol 2016; 32: 379-381

[44] Inoue H, Shiwaku H, Kobayashi Y et al. Statement for gastroesophageal reflux disease after peroral endoscopic myotomy from an international multicenter experience. Esophagus 2020; 17: 3-10

[45] Chandan S, Mohan BP, Chandan OC et al. Clinical efficacy of per-oral endoscopic myotomy (POEM) for spastic esophageal disorders: a systematic review and meta-analysis. Surg Endosc 2020; 34: 707-718

[46] Kahrilas PJ, Bredenoord AJ, Carlson DA et al. Advances in management of esophageal motility disorders. Clin Gastroenterol Hepatol 2018; 16: $1692-1700$ 